ducing charges may very well lead to a requirement that libraries become selfsupporting.

In her paper on charging practices in universities, Sandra Rouse qualifies the fee concept. She notes that "while the current environment may dictate charging library patrons for on-line reference services, we believe that future improvements in on-line systems will result in the library's absorbing an increasing percentage of the total cost."

There is little doubt that the public library, as we have known it, is in jeopardy. It is threatened by lack of funding, lack of public support, and by computers and electronic technologies. Drake's conclusion that "policy makers are likely to seek a compromise position between fully subsidized library service and fee for service" seems to me a very likely scenario for the future. Although Drake does not say so, the next question this raises is: What is the optimum division between these two sources of revenue? One would hope that another "practical perspective" would address this issue, which will be a real issue for library administrators.

The discussions of fees in various types of libraries vary in their relevance and interest. James Dodd's piece on information brokers highlights the paradoxical nature of the relationship between information brokers and public libraries. Rouse's paper summarizes charging policies in ten universities. But the paper on the Dialib project, which presents guidelines for introducing online services, is only peripherally related to charging fees.

This volume is recommended to those concerned with the future of libraries. It is especially recommended for the questions raised by both Drake and Blake and for Pfister's economic analysis. - Sara D. Knapp, State University of New York at Albany.

Blackwell, James E. Mainstreaming Outsiders: The Production of Black Professionals. New York: General Hall, 1981. 345p.

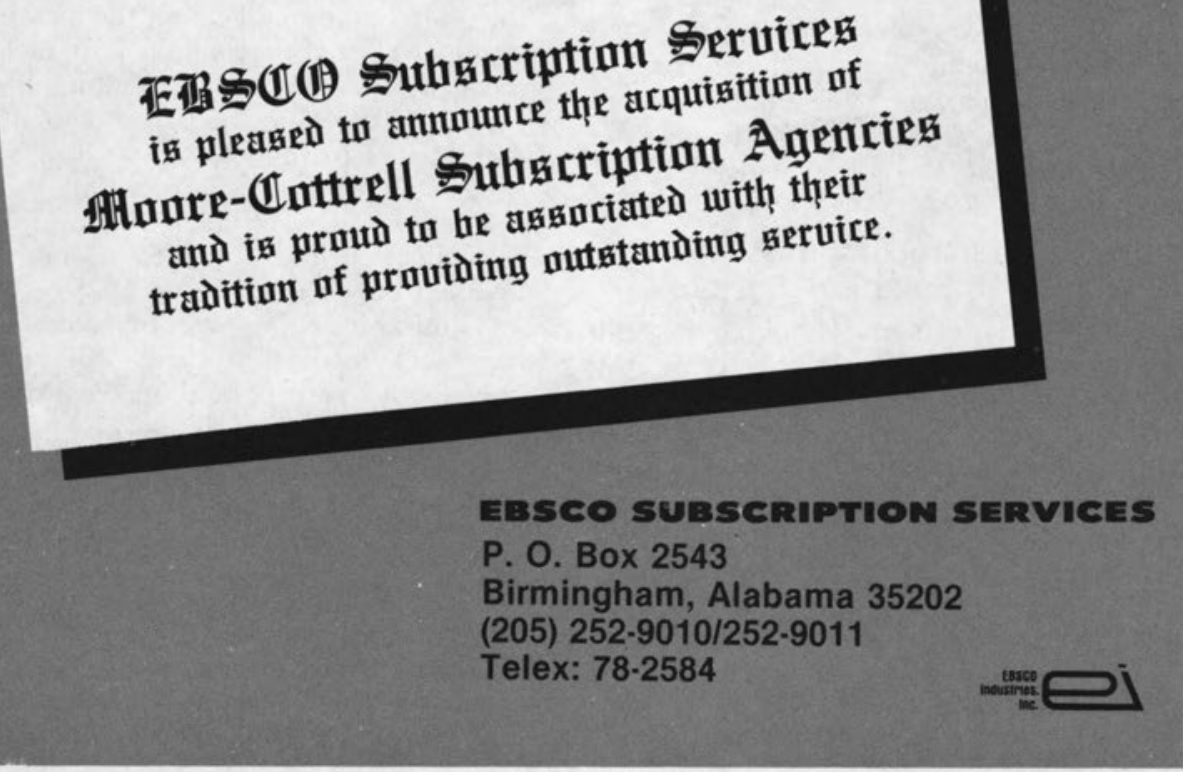



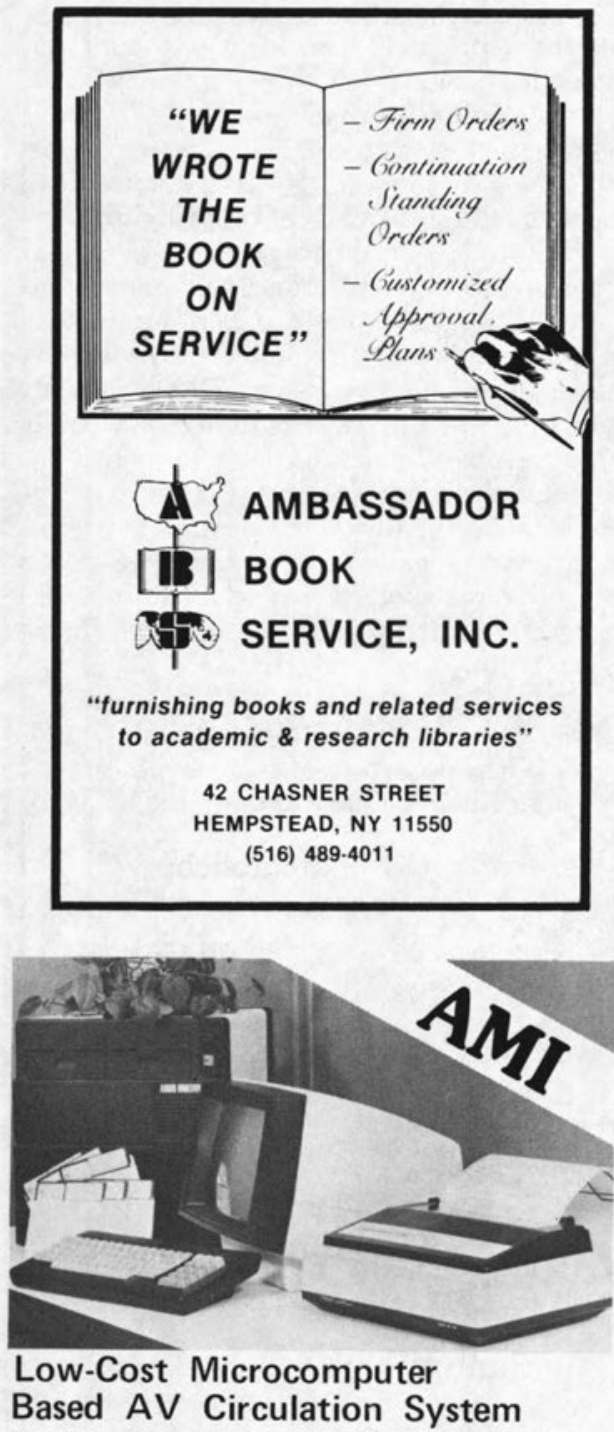

Replace outdated manual booking methods for as little as \$129 a week! With AMI you can improve service to your customers, keep more complete and accurate records, increase inventory turnover, reduce labor expense and speed up response time. AMI is the truly low-cost way to modernize your operations and save money. Call TOLL FREE 800/323-7520*

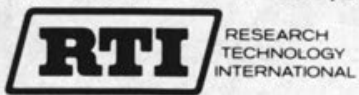

4700 Chase, Lincolnwood, Illinois 60646 •Illinois, Alaska, Hawaii Call 312/677-3000
$\$ 30.95$. LC $81-82121$. ISBN $0-930390$ 39-3.

The focus of Dr. Blackwell's scholarly study is upon access by blacks to education for the professions during the 1970s.

The author selects eight professions: medicine, dentistry, optometry, pharmacy, veterinary medicine, engineering, law, and social work. All of the publicly available documentation on recruitment, admissions, degrees granted, financial aid, and special programs for blacks and other minorities (especially reports by professional associations and the government) are examined to assess the situation in each field.

For each of the professions, detailed information on enrollments for each academic year of the $1970 \mathrm{~s}$ is provided, and the data are carefully analyzed. The eight professions are examined for current racial composition, the peculiar problems that entry into each presents for minority-group members, and whatever reasons might account for the ups and downs of black enrollments during the decade.

Blackwell takes note of gains where gains have been made, but they have been, for the most part, pathetically modest. He posits a hypothetical "parity" at somewhere between 11 and 12 percent. That is, the total black population of the United States is about this percent therefore, if a profession were fully integrated, one could expect the members to be about 11 or 12 percent black. In fact, only social work ever achieved anything like this level of parity (and the percentage of black enrollments in schools of social work has been declining during the past three years).

The proportion of black students in medical colleges in the United States more than doubled between 1969 and 1979, certainly an admirable achievement by all concerned, but black medical students still represent only about 6 percent of all medical students. As late as 1967, approximately 83 percent of the 6,000 black physicians then in practice had received their medical training at one of two traditionally black institutions, Howard University Medical School or Meharry Medical College in Nashville. Even at present, these two institutions account for 40 percent of all black medical faculty in the United States and turn out more black dentists than any dozen other dental schools combined. 


\section{In 1982}

\section{3,000 new titles in science and technology}

and

\section{3,000 new titles in the social sciences} are accessed for the first time in

\section{The Catalogue of British Official Publications Not Published by HMSO 1982}

and are available on demand or on standing order on microfiche.

These are books, serials and documents issued by over 350 official British agencies and are NOT listed in:

The HMSO Catalogues

The British National Bibliography

NTIS

or in any other Catalogue

Catalogue of British Official Publications Not Published by HMSO 1982

6 bi-monthly issues and clothbound annual cumulation $\$ 260$

Please ask for a free specimen issue of the Catalogue and information on special collections of documents on microfiche on Energy, Transport, Social Problems in Urban Areas, Equality of Opportunity (Race, Sex and Age Discrimination in Britain) and Bibliographies and Reading Lists.

\section{Chadwyck-Healey Inc}

623 Martense Avenue, Teaneck NJ 07666. Telephone: (201) 6921801 
In optometry, only 1 percent of the profession is black and in veterinary medicine only about 1.7 percent (with currently about 85 percent of all black veterinarian graduates from one institution-Tuskegee). Fewer than 2 percent of American engineers and fewer than 2 percent of our almost 600,000 lawyers are black.

For the eight professions that he studies, Blackwell makes a strong case that while progress toward "parity" has been made, it has been excruciatingly slow.

In a separate chapter on the production of black doctorates during the 1970s, he demonstrates that a situation similar to that of the professions existed in every field and in every state. At mid-decade, six out of every ten doctorates earned by blacks were in education.

Blackwell calls for increased involvement by government, foundations, and private industry in improving access to professional education for blacks, but his expectations of the Reagan administration fall considerably short of the optimistic.

Nowhere is librarianship mentioned in Blackwell's research, but his useful volume provides the data against which the library profession can measure its own accomplishments in "mainstreaming outsiders."-John Farley, School of Library and Information Science, State University of New York at Albany.

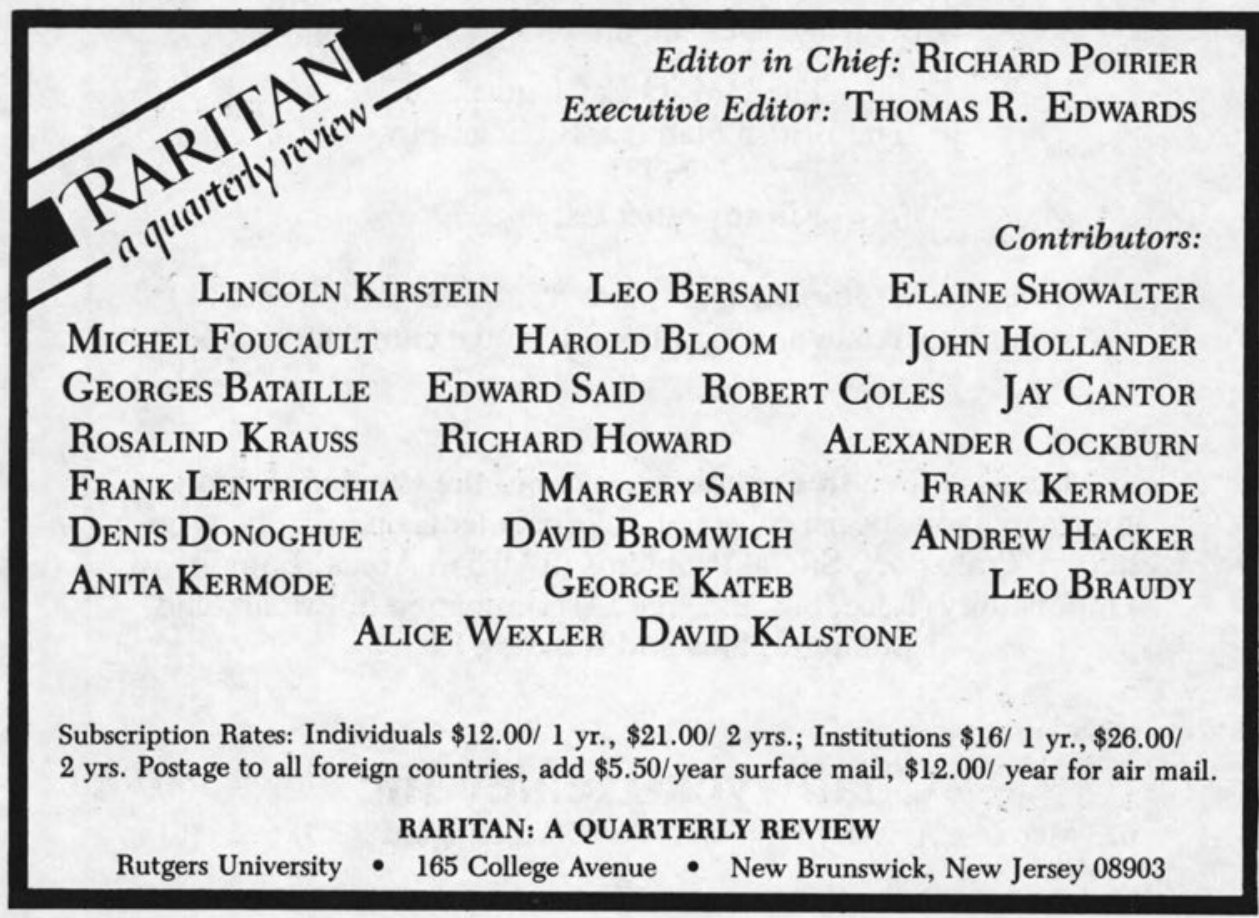

